\title{
Global Governance versus Domestic Governance: What Roles for International Institutions?
}

\author{
European Journal of Development Research \\ vol.14, n², December, p.173-182
}

Jean-Pierre Allegret Associate Professor

GATE UMR 5824 - CNRS and University Lumière Lyon 2, France

Philippe Dulbecco Associate Professor

CERDI UMR 6587 - CNRS and University of Auvergne Clermont 1,France

\begin{abstract}
Since the late $80 \mathrm{~s}^{\prime}$, emerging economies are striking by a recurrent instability of their financial system. The main lesson is that the domestic institutional infrastructure represents a critical condition necessary for successful liberalization. This critical condition refers to what we agree to call the "domestic governance" approach. The traditional answer provided in order to deal with this instability refers to the so-called "new international financial infrastructure". This initiative seems insufficient because it does not take into account the degree of adaptability of the prevailing domestic institutions. The purpose of our paper is to propose an analytical framework aimed at studying the relationship between "domestic governance" and "global governance". The challenge becomes to organize a multi-speed financial liberalization process in which capital controls could play a decisive role.
\end{abstract}

An earlier version of this paper has been presented at the International Conference on Global Economic Transformation after the Asian Economic Crisis, May 27-28, 2000, Hong-Kong. We thank the participants for their remarks and suggestions. 


\section{Introduction}

Financial crises have renew the debate on the benefits of financial liberalization in emerging economies. One of the main lessons is that institutions matter. From the point of view of international financial institutions (IFIs), that means that it is necessary to go beyond the Washington Consensus and to modify their approach to financial liberalization in order to integrate the role played by institutional factors. In this perspective, if the Bretton Woods institutions nowadays promotes the sequential approach to financial liberalization or the "second generation reforms", the main answer to this challenge is based on a "global governance" approach through the new international financial architecture (NIFA). The purpose of the NIFA is twofold: on the one hand, it promotes an orderly financial liberalization process on a worldwide scale; on the other hand, the NIFA invests the IFIs with the power of organizing international financial liberalization. From our point of view, these global initiatives are insufficient because they underestimate the consequences of the radical domestic changes induced by the financial liberalization for emerging economies.

Institutions may be considered as behavioral regularities associated with a set of rules, norms and routines. According to Schotter, the notion of institution may indicate: " $a$ regularity in social behavior that is agreed to by all members of society, specifies behavior in specific recurrent situations and is either self-policed or policed by some external authority" (1981, p.11). Institutions thus represent the means by which the agents, who ignore each other's actions and expectations, obtain the information that enables them to co-ordinate. The important point here is that institutions thus represent an essential element, a necessary condition, for the harmonious functioning of the markets. Institutional changes accompanying financial liberalization may consequently lead to a deterioration comparing to the initial situation because "various institutions and social expectations change at different speeds, particularly when there is a mix of exogenous and endogenous forces, as when global markets interact with domestic 
policies [...].The central problem to be addressed [...] is variable institutional adaptation" (Jacobs, 1999).

This variable institutional adaptation refers to what we agree to call the "domestic governance" approach. When we consider it explicitly, a new challenge coming from the difficulties engendered by the financial globalization appears: the question becomes how to ensure the compatibility between the standardization of financial practices implied by the dominant role now played by international investors, and the adaptation at a specific rhythm in each economy, according to the critical role played by the domestic institutions during transition.

The purpose of our paper is, in this perspective, to propose an analytical framework aimed at studying the relationship between "domestic governance" and "global governance". This analytical framework rooted into the institutional economics, deals with the interaction between institutions and markets.

The remainder of the paper is structured as follows. Section 2 proposes a critical assessment of the regulating market behavior role played by the NIFA. Section 3 introduces the analytical framework aimed at studying the dynamic institutional component of the financial reforms process. New foundations for international capital controls are proposed in section 4. Section 5 concludes.

\section{The new international financial architecture approach: a global governance answer}

The NIFA comprises seven building blocks (Camdessus, 1998): (i) the capacity of the authorities to discipline and to channel the market forces liberalized by globalization; (ii) the integration in the global economy which avoids the marginalization of the countries and thus represents a pre-condition for development; (iii) the universal consensus on the importance of an increasingly open and liberal system: each economy gets a net benefit from liberalization; (iv) the "golden rule" of transparency, "a key for modern management, economic 
success, and rational behavior of global markets" (p.3); (v) the good governance; (vi) a set of standards and codes of best practices; (vii) the necessity to organize cooperation between international institutions and between these institutions and supervisors.

Pillars (iv) to (vii) are particularly important because -focusing on the questions of information and transparency- they allow the market discipline to exercise its pressure on economic agents. Indeed one of the most obvious lessons from the most recent financial crises is that market failures are particularly important in the international economy. These crises have highlighted both the significance of the deficiency of the pertinent information conveyed to the market, and the lack of transparency of market mechanisms. These major market failures are the main sources of a destabilization process: first because the capacity of the market to maintain discipline is corrupted by the unreliability of the available information, and second because asymmetric information promotes blind herd behavior and panic runs, causing massive indiscriminate reversals of capital flows.

The NIFA gives now to international institutions a new role: to internalize the negative externalities engendered by private markets by producing information about states situations and private markets evolutions. This role, however, implies that the IFIs become market institutions: their intervention represents a pre-condition in order to obtain mature markets where asymmetric information is limited. This aim is moreover clearly confirmed by the IMF: production of information and international standards hold "the promise of better informed lending and investment decisions, increased accountability of policy makers and better policy making..." (IMF, 1999). By managing the production information process, the public international institutions contribute -at the global level and from an institutional point of view- to the reduction of uncertainty and consequently provide solutions to the formation and revision of individual plans processes ${ }^{1}$.

In the same line of thought, the Group of 22 explains that "transparency and accountability help to improve economic performance" (Group of 22,1998). Transparency and accountability rely on 
information production in order to reduce asymmetric information and promote market discipline. Transparency can be defined as "a process by which information about existing conditions, decisions and actions is made accessible, visible and understandable" (ibid.); transparency is then central to an efficient allocation of resources. Accountability is also a key element of the market discipline because it allows us "to justify and accept responsibility for decisions taken" (ibid.).

In summary it is today hardly controversial that international financial organizations and supervisory institutions have, since 1994, spearheaded efforts to increase the flow of accurate and comprehensive information and to improve the transparency ${ }^{2}$.

From this point of view, there is no doubt that the NIFA has made some progress in promoting and monitoring an orderly liberalization process. But this approach says nothing about what we consider to be the main challenge of the liberalization process, that is, the necessity to take into account the institutional constraints which characterize any liberalization processes considered as a transition process.

\section{Financial liberalization and institutional changes: a dynamic perspective}

Let recall that institutions represent "orientation points", which have authority to render compatible actions as much as individual expectations in a market process characterized by uncertainty.

It is thus necessary to render the idea of institutional change -implied by the financial liberalization- compatible with that of the institution, understood as a permanent orientation point. Although this problem is not specific to emerging economies, it exists for them in very particular terms because, unlike in developed countries, institutional changes are not incremental, but radical ${ }^{3}$. There is, indeed, an asymmetry between abandoning -rapidly destroying- previous institutions, and adopting -slowly constructing- new ones. The consequence is that individuals incur the risk of being confronted, sometimes over long 
periods, by the lack of rules that enable them to co-ordinate their plans efficiently. The adoption of market mechanisms thus shows a deterioration in their positions.

Furthermore, one must take into account the fact that the adoption -the transfer-, just like the creation of new institutions, is subject to delays: delays of implementation in the first case, and delays of construction in the second. Yet, the amount of economic change possible per unit of time is always limited, because agents have limited training capacities. And once again, this constraint is bigger in emerging economies.

It may be useful here to recall the distinction, made by Lachman (1970), between legal norms or designed institutions, which are "the products of legislation and other manifestations of the 'social will'" (Lachman, 1970, p.69) and spontaneous or "non-designed institutions", understood as "recurrent patterns of conduct" (ibid., p.75)4. Thus, if it is always possible, in theory and in practice, to imagine a situation in which an economic or political authority decides to implement new institutions -for example a bankruptcy court- the benefits expected from this type of measure are a controversial issue. Indeed, inasmuch as such a policy is, by definition, limited to designed institutions, its success depends on the capacity of these new elements to meet the demand for change in institutions not yet designed. The difficulty comes from the fact that, if the transformation of designed institutions is, in general, both radical and fast, that of non-designed institutions is of an incremental nature, and is necessarily subject to path dependence constraints. The reason is that, apart from the fact that individuals only accept to subject themselves to changes in the rules of the game when they find an interest, individual behavior is the result of a cumulative process of collective learning, which often started generations before, i.e. of a learning "that have passed the slow test of time" (North, 1994, p.364). Therefore, the adoption of institutions is in no case equivalent to their institutionalization.

Finally, the question of institutional order, and of its unity, arises: if institutional order is the product of the complementarity of institutions, what are the integrating forces of institutions, 
and under which circumstances do these forces cease to work? The analysis of the process of financial globalization requires us to specify the conditions of the coherence of institutional order, because the system's components evolve at different speeds.

The solution to this problem is also the solution to what we call the permanency-flexibility dilemma faced by the emerging economies ${ }^{5}$. If institutions do not possess the same status or do not exactly perform the same functions ${ }^{6}$, according to Lachmann (1970), they nevertheless share the same flexibility property in relation to the idea of permanence of the entirety. The permanency of the institutional and legal order in no way requires the permanence of each of its components. The question which is thus posed is that of the compatibility of institutional change with a permanence of the structure.

For most emerging economies, the main challenge from the financial liberalization is to reconcile a higher degree of market discipline (in an outsider logic) and the pre-eminence of intermediation based on an insider logic (or a relationship financial system), which has proven itself for economic development. Taking into account the path dependency constraints faced by each economy, requires that we focus on the incremental nature of this process contrary to what is proposed by the so-called "big bang" or "shock therapy" approaches. This raises non only the question of the resilience of financial systems in emerging economies, i.e. of their capacity to change structurally while preserving their basic properties, but also the question of the capacity of each country to implement reforms at a specific rhythm. Such analysis is once again focused on the institutional component of the process.

More precisely, the adoption of an appropriate prudential regulation -based on a sound accounting structure and efficient control institutions- the reduction of the public authorities' involvement in financing, and the improvement of incentives for banks' stakeholders shareholders, managers and creditors- to develop competitive profit-seeking behavior, are measures susceptible to modify the banking behavior in order to reduce some banking 
inefficiencies. But, at the same time, the main challenge of such a liberalization process is to preserve the advantages of the strong bank-firms relationship. The reduction of information asymmetries in such a system decreases the borrowing costs for firms and promote a cooperative behavior in case of financial difficulties?.

Thus, the lessons drawn from the Asian crisis, but also from the behavior of numerous banks in Latin American countries, lead us to stress the following point: any reform concerning the banking behavior faces an important challenge. It is to find the appropriate tradeoff between a strong financial constraint -which could slow down the investment- and a soft financial constraint -leading to an inefficient resources allocation. In other words, promoting banking reforms, whose the main objective is to bring banking practices in emerging economies to converge towards the practices adopted in numerous mature markets, is not necessarily the more efficient way to favor economic growth. Interpersonal relationships are less prominent in developed countries because of the presence of liquid financial markets with a strong legal rules and contracts enforcement mechanisms.

Because of the importance the asymmetric information in emerging economies, which impede the development of financial markets, the particular status of the financial intermediation must be stressed. The financial intermediary represents the main legal designed- institution, which may authorize the development of the contractual sphere -the market development- whilst guaranteeing the coherence and the permanence of the institutional order necessary for carrying out individual transactions. The difficulty lies in the fact that each component of the dilemma refers to a specific analytical level: the global one concerning flexibility, the domestic one for permanency.

The question consequently becomes how to explain how the NIFA is able to provide the instruments which authorize each emerging economy to reach a liberalized financial market in a incremental manner i.e. without sacrificing their institutional order fundamentally based on a strong financial intermediation. The solution proposed implies that we consider a multi- 
speed financial globalization process in which each country may choose its own liberalization agenda profiting from the patterns of coordination offered by the global institutional infrastructure.

\section{Institutional change and capital controls}

Traditionally, capital controls are used for two major reasons. First, they allow to attain a second-best result because of markets imperfections. Second, they limit the negative externalities due to the fact that financial markets are prone to recurrent crises induced by herd behavior and coordination failures. From our point of view, a third motive for capital controls seems possible. Indeed, one of the main element of the multi-speed globalization process is the definition of an internationally accepted framework required for the liberalization of international capital movements in which the question of capital controls is explicitly integrated. From this perspective, capital controls could create a wedge between domestic and global financial markets in order to improve the resilience of the former during institutional changes periods. More precisely, if we take into account the necessary delay of adaptation following the creation of new institutions -mainly here new market financial practices- capital controls could reduce the negative externalities due to the discrepancy between this necessary learning and the fact that these practices are extensively used in mature markets whose investors promote the globalization process. Without such a wedge, the behavior of the international investors -even if rational- could destabilize the financial systems of emerging economies by introducing financial practices which do not correspond to the structural characteristics of the domestic financial systems.

The main point is that IFIs should integrate in their mandates the questions of capital account convertibility and the imposition of capital controls. From the institutional dynamic perspective adopted in this paper, two main factors justify such an intervention. 
First, international financial integration engenders centripetal forces which can destabilize the international financial system. Indeed, if emerging economies believe that benefits from integration are superior to costs -without distinguishing between short and long terms horizons- then they will prefer a rapid integration in order to attract a share of the world saving. This strategy could imply negative externalities on the international financial system (via contagion) if their financial infrastructure is insufficiently developed.

Second, capital controls a priori contradict the so-called "Wall Street paradigm" according to which the globalization of financial markets induces only benefits via the optimal allocation of resources. As a result, the imposition of capital controls could consequently be interpreted by the markets as a negative signal and the cost of international loans (credit as well as bonds) can increase ${ }^{8}$. So, centripetal forces and negative signal do not incite the authorities of emerging economies to adopt a prudential strategy of liberalization. In this perspective, when they impose capital controls, it is for a "market preservation" (Cohen, 2000) -i.e. a defensive strategy- and not, as we propose here, a "reforms promotion" strategy".

In this context, the IMF must develop a precise and mandatory code of good practices concerning capital movements, in order to avoid such heavy and sudden destabilizing inflows and outflows. The opening of the capital account must be carried out under the surveillance of the international institutions which provide a common framework to the international community and, at the same time, respect the variable institution adaptation in each country. At the Hong Kong annual meeting in September 1997, a first step in this direction was proposed by the IMF.

The Board of Governors published a communiqué entitled "Statement of the Interim Committee on the liberalization of capital movements under an amendment of the articles". In this statement, the Board affirmed the necessity "to add a new chapter to the Bretton Woods agreement" and, in order to promote an orderly financial liberalization, to adapt the capital account liberalization to "the circumstances of individual countries, thereby 
maximizing the chances of success, not only for each country but also for the international monetary system". This last quotation suggests that the IMF admits the global public good approach stressed above: whenever a country wishes to open its capital account to benefit from globalization, it is important first to check that its financial structure and macroeconomic policy are ready. Otherwise, instability in this country can be contagious because of the existence of externalities coming from globalization. But without a precise framework on capital account liberalization, each country would be incited to compete with others in order to decrease its international lending costs.

In order to reduce the negative effects coming from these controls ${ }^{10}$, the IMF will have to propose a broad set of principles and guidelines concerning their uses. Principles and guidelines should be negotiated multilaterally, but each member-country should be free to use them after a consultation with the IMF. As suggested by Cohen (2000), the guidelines must answer three questions: (i) what restraints on capital mobility may be permitted?; (ii) under what circumstances?; (iii) using what procedures? The negative signal linked to the imposition of capital controls should be minimized if the IMF integrates them in a liberalization strategy. The intervention of the IMF would serve as a guarantor of the credibility of the strategy adopted by domestic authorities. Capital controls would become a positive signal for markets, i.e. the illustration of the prudent strategy adopted by authorities in emerging economies, but under the surveillance of the IMF.

The main implication of this proposition is that capital controls -and more broadly capital account convertibility- must be under the jurisdiction on the IMF. More precisely, in the same way that article VIII of the Bretton Woods agreement establishes current account convertibility and article XIV specifies the transitional measures towards a total convertibility, a new article, to be written and related to the capital account convertibility, would institutionalize the appropriate sequencing of the financial opening of the member countries and the rules of the game concerning capital controls, favoring thus a sustainable 
integration in the world economy. This new article should specify to what extent the IMF has the responsibility of monitoring progress towards capital account convertibility ${ }^{11}$.

This new responsibility may be interpreted as an implicit way of constraining national authorities to liberalize their economy. We propose here another interpretation. Instituting a code of good practices indeed offers the advantage of stabilizing the relationship between the various agents in the financial markets, since internationally recognized standards model their behavior. As a result, far from promoting a global capital market that escapes any control, an enhanced surveillance and careful Fund management of capital account convertibility would help ensure a gradual and successful integration of each country in the global financial community. That also means that the IMF must develop its analysis of the use of different types of capital controls by member countries ${ }^{12}$.

\section{Conclusion}

Financial liberalization requires an in-depth analysis of the relationship between domestic governance and global governance. On the one hand, institution transfers from mature markets to emerging markets are inefficient because they don't take into account the history of the financial system in each economy. On the other hand, the financial globalization tends to induce, not only a standardization of financial practices, but also a similar approach to financial liberalization. One of the main objectives of the global governance should be to allow a tradeoff between the domestic nature of the institutional framework and the globalization process which does not recognize it. From this perspective, capital controls could constitute a relevant tool in order to promote an orderly financial liberalization process. 


\section{References}

Allegret J.P., Courbis B. and Dulbecco P. (1999), "Financial Liberalization and Stability of the Financial System in Emerging Markets: the Institutional Dimension of Financial Crises", Communication a the Conference Global Development Network, The World Bank, Bonn, December 5-8.

Camdessus M. (1998), "Toward A New Financial Architecture For A Globalized World", Adress At The Royal Institute of International Affairs, May, London.

Cohen B. (2000), "Taming The Pheonix: Monetary Governance After The Crisis", in G. Noble and J. Ravenhill (eds), The Asian Financial Crisis and The Architecture of Global Finance, Cambridge University Press, forthcoming.

Grilli V. and Milesi-Ferretti G. (1995), "Economic Effects and Structural determinants of Capital Controls", IMF Staff Papers, 42, 3, pp.517-551.

Group of 22 (1998), Report of The Working Group on Transparency And Accountability, October.

International Monetary Fund (1997), Statement of The Interim Committee On The Liberalization of Capital Movements Under An Amendment Of The Articles, Communique of the Interim Committee of the Board of Governors, Hong-Kong, September.

International Monetary Fund (1999), International Standards And Fund Surveillance - Progress And Issues, Washington DC, August.

International Monetary Fund (2000), Country Experiences With The Use And Liberalization of Capital Controls, January, Washington DC.

Jacobs S. (1999), "The Second Generation of Regulatory Reforms", Communication to The Conference on Second Generation Reforms, IMF, November 8-9.

Lachmann L. (1994), “On The Economics of Time And Ignorance”, in Boettke P., Prychitko D. (eds.), The Market Process, Essays In Contemporary Austrian Economics, Edward Elgar.

Lachmann, L. (1970), The Legacy of Max Weber, Heinemann, London.

North D. (1994), "Economic Performance Through Time", American Economic Review, June, Vol. 84, n³.

Schotter A. (1981), The Economic Theory of Social Institutions, Cambridge University Press, New York.

Tarapore S.S. (1998), “An Indian Approach To Capital-Account Convertibility”, in S. Fischer (ed), Should The IMF Pursue Capital-Account Convertibility?, Essays in International Finance, n`207, May, pp.66-75. 


\section{End-notes}

${ }^{1}$ This fact is by another way confirm by the first building block.

${ }^{2}$. Among the main measures taken by the International Monetary Fund, we can refer to: (i) the Special Data Dissemination Standard (SDDS) approved by the Interim Committee in April 1996; (ii) Press Information Notices (PINs) (May 1997); the Policy Framework Papers (PFPs); the letters of Intend (LOIs). The two latter documents describe the policies negotiated with the Fund and followed by the members who requested financial support from the IMF. The Financial Sector Stability Assessments (FSSAs) and the Financial Sector Assessment Program (FSAP). The creation of a transparency report called "Report on the implementation of standards and codes" (RISC) which is an assessment of countries' disclosure practices concerning both key macroeconomic data and the progress made by these countries in observing the standards.

${ }^{3}$. Radical institutional changes are due to the fact that financial liberalization is a domestic answer to external pressures, i.e. to the globalization process.

${ }^{4}$.One recognises Menger's distinction between pragmatic and organic institutions.

5 . Our analysis is based on that of Lachmann.

${ }^{6}$. Some institutions are more fundamental than others, in the sense that they are core elements of a market economy (Lachmann, 1994, p.50).

${ }^{7}$. See Allegret, Courbis and Dulbecco (1999).

${ }^{8}$. See the immediate impact of the capital controls in Malaysia.

${ }^{9}$. Capital controls based on market preservation of market are imposed in periods of crisis. See the experiences of Thailand ( May 1997) and Malaysia (September 1998). We do not suggest that this type of control is necessarily ineffective, but they do not respond to the multi-speed integration strategy.

${ }^{10}$. In addition to the negative signal effect, some empirical studies showed that capital controls can be used by inefficient governments which try to protect their dominant position. See for example Grilli and Milesi-Ferretti (1995).

11. This comparison between current account convertibility and capital account convertibility does not imply an analogy between them. We do not ignore the specificity of capital account convertibility. See Tarapore (1998).

12. A first step in this direction was the publication of a report in January 2000. Let us also recall that capital controls are now a part of the new architecture project. The IMF has explicitly declared its intentions to evaluate the conditions in which capital controls can be used in order to promote an orderly capital account liberalization. 